\title{
Prevalence and Antibiotic Susceptibility Pattern of Pathogens Causing Ventilator-Associated Pneumonia in Patients attending a Tertiary Care Hospital in South-Eastern Rajasthan, India
}

\author{
Yogendra Kumar Tiwari and Adhunika Singh* \\ Department of Microbiology and Immunology, S.R.G. Hospital and Medical College, \\ Jhalawar, Rajasthan, India \\ *Corresponding author
}

\section{A B S T R A C T}

\section{Ke ywords}

Antibiotic therapy,

Nosocomial

infection,

Pathogens, Tertiary-

care hospital

Article Info

Accepted:

30 October 2019

Available Online:

10 November 2019
Ventilator-associated pneumonia (VAP) is the most common nosocomial infection diagnosed in the intensive care unit (ICU) and in spite of advances in diagnostic techniques and management it remains a common cause of hospital morbidity and mortality. While critically ill patients experience a life-threatening illness, they commonly contract ventilator-associated pneumonia. This nosocomial infection increases morbidity and likely mortality as well as the cost of health care. This article reviews the literature with regard to underlying clinical condition, prevalence, diagnosis and antibiotic susceptibility pattern of the most commonly isolated pathogens associated with VAP. This prospective observational study was carried out over a period of 1 year. VAP was diagnosed using the clinical pulmonary infection score. Endotracheal aspirate (ETA) and bronchoalveolar lavage (BAL) samples of suspected cases of VAP were collected from ICU patients and processed as per standard protocols. The incidence of VAP in our study was $57.27 \%$. COPD was the commonest underlying condition associated with VAP followed by post operative illness \& respiratory failure. The incidence of VAP increased as the duration of mechanical ventilation increased and there was a total agreement in bacteriology between semi-quantitative ETAs and BALs in our study. Most commonly isolated organism was Acinetobacter baumanii followed by Pseudomonas aeruginosa and Klebseilla pneumoniae. The present study conclude that determination of the organism profile and their antibiotic sensitivity can go a long way in prescribing appropriate regimen which could be life saving. Another important aspect in VAP group of patients is that if the antibiotic therapy is delayed, there could be excessive mortality. Early report regarding antibiotic susceptibility patterns could be significant in deciding the antibiotic regimens. VAP is a serious problem in the ICU leading to longer hospital stay higher treatment costs and increased mortality and morbidity. Better knowledge of local patterns of pathogens causing VAP can help facilitate treatment choices.

\section{Introduction}

Ventilator-associated pneumonia (VAP) is a common nosocomial infection in intensive care units (ICUs). VAP is defined as pneumonia that occurs $48 \mathrm{~h}$ or more after endotracheal intubation or tracheostomy, caused by infectious agents not present or incubating at the time mechanical ventilation was started. It can be of two types: (i) earlyonset VAP which is defined as VAP that 
occurs within the first 4 days of ventilation, and (ii) late-onset VAP which is defined as VAP that occurs more than 4 days after initiation of mechanical ventilation. ${ }^{\mathbf{1}}$ The objective of this study is to describe the microbiology of VAP in tertiary-care hospital ICU of Jhalawar, Rajasthan for a period of one year. Intensive care unit (ICU) hospitalisations impose a high risk of acquiring healthcareassociated infection (HAIs), most commonly nosocomial pneumonia. It is necessary to understand how and when the ICU admitted, mechanically ventilated patients develop VAP and which micro-organisms are responsible for causing VAP. The microorganisms responsible for VAP and their drug resistance vary between individual hospitals wards, between regions of a state and across India. Thus, there is a need for local surveillance data, taking into account a detailed analysis of etiologic agents responsible for VAP. VAP requires rapid diagnosis and initiation of the appropriate antibiotic treatment, since studies have shown that the delayed administration of appropriate antibiotic therapy in patients with VAP has been associated with excess hospital mortality. ${ }^{2}$

Therefore, our objective is to determine the incidence of VAP, to assess the risk factors and attributable mortality associated with VAP and to find out the various bacterial pathogens causing VAP in the medical ICU of our institute.

\section{Materials and Methods}

This prospective, observational study was done in the Department of Microbiology, Jhalawar Medical College, in association with the tertiary care teaching hospital of Jhalawar, Rajasthan for a period of 1 year (Aug 2017Aug 2018). All symptomatic patients on mechanical ventilation for more than $48 \mathrm{hrs}$ admitted in the medical and surgical ICUs were taken for study. Modified clinical pulmonary infection score (CPIS) score was then studied as a screening method to clinically diagnose VAP. Detailed history including the name, age, sex, underlying clinical condition, date of admission to the ICU, date of indoor admission, any history of previous antibiotic intake, the treatment being administered in the ICU and clinical outcome of each patient was noted. Any lower respiratory tract infection that developed after $48 \mathrm{~h}$ of mechanical ventilation and was judged not to have been incubating before mechanical ventilation was taken as VAP.

VAP rate was defined as the number of VAPs/1,000 ventilator days. The diagnosis of VAP was based on clinical and microbiological criteria. A clinical suspicion of VAP was made in patients with modified CPIS score >6. Broncho-alveolar lavage (BAL) was taken as the sample of interest for diagnosing VAP. Gram stain preparations were made from all BAL samples and examined first under low power to determine the presence and type of cells in the specimen and then observed under oil immersion field. The relative number of micro-organisms and their morphologies were recorded. All the samples were inoculated semi-quantitatively on blood agar, MacConkey agar and chocolate agar and incubated aerobically at $37 * \mathrm{C}$. Growth $>105 \mathrm{CFU} / \mathrm{ml}$ was taken as the cut-off threshold for BAL. Samples showing growth less than these thresholds were assumed to be due to colonisation or contamination. In case of significant growth, the isolated colonies were subjected to gram stain. Identification and AST pattern of bacterial isolates thus obtained from 110 intensive-care hospitalised patients were processed on Vitek 2 system (Biomerieux, France).

\section{Results and Discussion}

Out of the 110 VAP suspected ICU admitted patients, samples of 63 patients yielded 
bacterial growth. The incidence of VAP in our study was $57.27 \%$. Out of the 63 cases, $19 \%$ developed early VAP whereas $38 \%$ developed late VAP. Highest number of patients developing VAP was due to COPD (17/21). 2nd most common cause for development of VAP was due to post operative illness (19/30). Likewise, respiratory failure (16/27), trauma (4/10), poisoning (1/7) and miscellaneous (6/15) were amongst the other causes. In relation to gender, the incidence of VAP was more among males (63\%) than females (36\%) and in different age groups the incidence of VAP was highest in patients more than 55 years of age $(76.19 \%)$.

Gram negative bacteriae were the most commonly isolated pathogens responsible for VAP. Amongst them, Acinetobacter baumanii was found to be the single most common organism isolated (21/63). Likewise, Pseudomonas aeruginosa (17/63), followed by Klebseilla pneumoniae (11/63), Citrobacter freundii (5/63), Eschericia coli (3/63), Proteus mirabilis (2/63) were isolated as other common pathogens. Amongst the Gram positive bacteriae, Staphylococcus aureus (4/63) was the only pathogen responsible for causing VAP, in our study.

In our study we noted that the association with VAP was highest in the age group of $>55$ years $(76.19 \%)$, followed by $46-55$ years (58.73\%), 36-45 years (46.03\%), 15-25 years $(28.57 \%)$ and $26-35$ years $(11.11 \%)$ respectively.

In our study, 63 out 110 ICU admitted patients developed VAP, the VAP rate being $57.27 \%$. In 2018, Sohal et al., concluded that out of the 100 patients admitted in their ICUs from December 2016 to January 2018, 39 patients developed VAP during hospitalisation. ${ }^{3}$

In 2017, Othman et al., conducted a study on ICU patients developing VAP for a period of 1 year and concluded that VAP occurred in 17 out of 48 patients $35.4 \%{ }^{4}$ In 2017 , Patil et al., conducted a study over a period of 1 year from April 1, 2011, to March 31, 2012. concluded that out of 267 patients on mechanical ventilator, $74(27.71 \%)$ patients developed VAP. ${ }^{5}$ In 2015, Chin et al., conducted a retrospective cohort study from April 1, 2007 , to May 31, 2010, which included 200 ICU admitted patients, 129 patients were diagnosed with VAP with $70 \%$ of cases constituting "late VAP" (diagnosis greater than 4 days after ICU admission). ${ }^{6}$ Airway intubation is associated with increased frequency of Gram-negative bacterial colonization of upper and lower respiratory tract with subsequent overgrowth and pneumonia. Non fermenters such as Pseudomonas spp. and Acinetobacter spp. were significantly associated with late onset VAP as observed by other workers but in our study even in patients with early onset VAP, Acinetobacter was the most common pathogen. In our study, the most common cause of VAP was Gram negative bacteriae of which Acinetobacter baumanii was most commonly isolated, followed by Klebsiella pneumoniae, Citrobacter freundii, Escherichia coli, Proteus mirabilis were isolated as other common pathogens. Amongst the Gram positive bacteriae, Staphylococcus aureus was the only pathogen responsible for causing VAP, in our study. In 2017, Patil et al., concluded that of the total 55 MDR isolates in VAP, 13(26.63\%) were Klebsiella, 11(20\%) Pseudomonas, 14(25.45\%) Acinetobacter, $8(14.54 \%)$ E. coli and $9(16.36 \%)$ coagulase positive $S$. aureus (COPS). ${ }^{7}$ In 2016, Mathai et al., performed microbiological evaluation on 109 respiratory samples collected from 94 patients suspected to have VAP infection. Gram-negative organisms were isolated in 95 samples, Gram-positive organisms in five samples while nine samples did not show any growth. On culture, the most common organisms grown were Acinetobacter (58 isolates, 53.2\%), Klebsiella (17 isolates, 
15.6\%), Pseudomonas (14 isolates, 12.8\%), and Escherichia coli (nine isolates, $8.25 \%$ ). Of the five Gram-positive isolates, one $(0.9 \%)$ was found to be methicillin-sensitive Staphylococcus aureus (MSSA) and 4 (3.6\%) were methicillin-resistant S. aureus (MRSA). Six (5.5\%) samples yielded fungal organisms, which included Candida albicans (in one isolate) and Candida nonalbicans (in five isolates). Fifteen patients had polymicrobial flora in their tracheobronchial secretions, namely, combinations of Gram-negative organisms, viz., Acinetobacter, Klebsiella and Pseudomonas. ${ }^{8}$

In 2012, Su Young Chi et al., showed that out of a total of 109 bacterial pathogens from 91 adult patients with VAP, who were admitted to the medical intensive care unit from January 2008 to December 2009, Staphylococcus aureus (44\%) was the most frequently isolated. Acinetobacter baumanii (30\%), Pseudomonas aeruginosa (12\%), Stenotrophomonas maltophilia (7\%), Klebsiella pneumoniae (6\%), and Serratia marcescens (2\%) were isolated from the transtracheal aspirates or bronchoalveolar lavage in patients with VAP. There was no significant difference of bacterial pathogens between early and late onset VAP. ${ }^{9}$

In 2010, Gadani et al., concluded that the order of prevalence of organism in their study was found to be Pseudomonas (43.2\%), Klebsiella $(18.91 \%)$, followed by MRSA, E. coli, Acinetobacter, MSSA and $S$. pneumoniae. $^{10}$

In the present study, Chronic Obstructive Pulmonary Disorder (COPD) stood out as the most common underlying condition leading to VAP, followed by post operative stay in ICU, respiratory failure, trauma and chronic ailments like diabetes mellitus, chronic renal diseases, Neurological diseases, hepatic diseases. In 2017, Li Chang et al., observed that age $>65$ years, smoke, coronary heart disease, diabetes, chronic obstructive pulmonary disease (COPD), ICU and hospital stay, and days on mechanical ventilation were risk factors of VAP, with age $>65$ years being the most common risk factor ${ }^{11}$ (Fig. 1 and Table 1 and 3).

Table.1 Patients with VAP according to age groups, gender and underlying clinical condition

\begin{tabular}{|l|c|c|c|c|c|c|c|c|c|}
\hline \multicolumn{1}{|c|}{$\begin{array}{c}\text { Underlying } \\
\text { condition }\end{array}$} & $\begin{array}{c}\text { Total no } \\
\text { of } \\
\text { patients } \\
\text { in ICU } \\
(110)\end{array}$ & $\begin{array}{c}15- \\
25 \mathrm{yrs}\end{array}$ & $\begin{array}{c}26- \\
35 \mathrm{yrs}\end{array}$ & $\begin{array}{c}36- \\
45 \mathrm{yrs}\end{array}$ & $\begin{array}{c}46- \\
55 \mathrm{yrs}\end{array}$ & $\begin{array}{c}>55 \\
\text { yrs }\end{array}$ & $\begin{array}{c}\text { Total no of } \\
\text { patients } \\
\text { developing } \\
\text { VAP (63) }\end{array}$ & $\begin{array}{c}\text { Patients } \\
\text { developing } \\
\text { VAP } \\
\text { Gender } \\
\text { M/F }\end{array}$ & $\begin{array}{c}\% \text { of } \\
\text { patients } \\
\text { developing } \\
\text { VAP }\end{array}$ \\
\hline Post operative & 30 & 0 & 2 & 4 & 9 & 15 & 19 & $13 / 6$ & 63.33 \\
\hline Trauma & 10 & 3 & 8 & 5 & 2 & 1 & 4 & $4 / 0$ & 40 \\
\hline COPD & 21 & 0 & 0 & 9 & 8 & 13 & 17 & $9 / 8$ & 80 \\
\hline $\begin{array}{l}\text { Respiratory } \\
\text { failure }\end{array}$ & 27 & 0 & 2 & 7 & 9 & 8 & 16 & $10 / 6$ & 59.25 \\
\hline Poisoning & 7 & 5 & 4 & 1 & 0 & 0 & 1 & $0 / 1$ & 14.28 \\
\hline Miscellaneous* & 15 & 0 & 2 & 3 & 9 & 11 & 6 & $4 / 2$ & 40 \\
\hline
\end{tabular}

* Diabetes mellitus, Chronic renal failure, Neurological illness, Liver disorders, etc

COPD - Chronic Obstructive Pulmonary Disease 
Table.2 Distribution of organisms isolated from patients with VAP

\begin{tabular}{|l|c|c|}
\hline \multicolumn{1}{|c|}{ PATHOGENS ISOLATED } & NO OF ISOLATES & \% OF ISOLATES \\
\hline GRAM NEGATIVE BACTERIAE & & 33.33 \\
\hline 1. Acinetobacter baumanni & 21 & 26.98 \\
\hline 2. Pseudomonas aeruginosa & 17 & 17.46 \\
\hline 3. Klebsiella pneumoniae & 11 & 7.93 \\
\hline 4. Citrobacter freundii & 5 & 4.76 \\
\hline 4. Eschericia coli & 3 & 3.17 \\
\hline 5. Proteus mirabilis & 2 & \\
\hline GRAM POSITIVE BACTERIA & & 6.34 \\
\hline 6. Staphylococcus aureus & 4 & \\
\hline
\end{tabular}

Table.3 Antibiotic susceptibility pattern of pathogens isolated in VAP

\begin{tabular}{|c|c|c|c|}
\hline PATHOGEN & $\begin{array}{c}\text { NO OF } \\
\text { ISOLATES }\end{array}$ & SENSITIVE & RESISTANT \\
\hline $\begin{array}{c}1 . \\
\text { ACITENOBACTER } \\
\text { BAUMANNI }\end{array}$ & 21 & $\begin{array}{l}\text { PB2O CO2O MRO10 } \\
\text { IMP11 L18 CF9 } \\
\text { CS14 CZD } 14 \text { PT10 } \\
\text { AMC15 TOB9 }\end{array}$ & $\begin{array}{c}\text { PB1 CO1 MRO11 } \\
\text { IMP1O L3 CF12 CS7 } \\
\text { CZD7 PT11 AMC6 } \\
\text { TOB12 }\end{array}$ \\
\hline $\begin{array}{c}2 . \\
\text { PSEUDOMONAS } \\
\text { AERUGINOSA }\end{array}$ & 17 & $\begin{array}{c}\text { PB17 CO17 MRO10 } \\
\text { IMP12 L8 CF9 CS9 } \\
\text { CZD10 PT10 AMC9 } \\
\text { TOB9 }\end{array}$ & $\begin{array}{c}\text { PB1 CO1 MRO8 } \\
\text { IMP6 L1O CF9 CS9 } \\
\text { CZD8 PT1O AMC9 } \\
\text { TOB9 }\end{array}$ \\
\hline $\begin{array}{l}\text { 3. KLEBSEILLA } \\
\text { PNEUMONIAE }\end{array}$ & 11 & $\begin{array}{c}\text { PB11 CO11 MRO10 } \\
\text { IMP9 L9 CF9 CS9 } \\
\text { CZD9 PT9 AMC8 } \\
\text { TOB8 }\end{array}$ & $\begin{array}{l}\text { PB2 CO2 MRO3 IMP4 } \\
\text { L4 CF4 CS4 CZD4 } \\
\text { PT4 AMC5 TOB4 }\end{array}$ \\
\hline $\begin{array}{c}4 . \\
\text { STAPHYLOCOCCU } \\
\text { S AUREUS }\end{array}$ & 4 & $\begin{array}{l}\text { Lz6 VA6 COT5 CD5 } \\
\text { OF4 E4 AMC4 AK4 }\end{array}$ & $\begin{array}{lll}\text { LzO VAO COT1 } & \text { CD1 } \\
\text { OF2 E2 AMC2 } & \text { AK2 }\end{array}$ \\
\hline $\begin{array}{l}\text { 5. ESCHERICIA } \\
\text { COLI }\end{array}$ & 3 & $\begin{array}{l}\text { PB2 CO2 MRO3 IMP3 } \\
\text { L3 CF2 CS2 CZD2 } \\
\text { PT2 AMC3 TOB2 }\end{array}$ & $\begin{array}{l}\text { PB1 CO1 MROO IMPO } \\
\text { LO CF1 CS1 CZD1 } \\
\text { PT1 AMCO TOB1 }\end{array}$ \\
\hline $\begin{array}{l}\text { 6. PROTEUS } \\
\text { MIRABILIS }\end{array}$ & 2 & $\begin{array}{c}\text { PB2 CO2 MRO2 } \\
\text { IMP2 L1 CF2 CS2 } \\
\text { CZD1 PT1 AMC2 } \\
\text { TOB1 }\end{array}$ & $\begin{array}{l}\text { PBO COO MROO IMPO } \\
\text { L1 CFO CSO CZD1 } \\
\text { PT1 AMCO TOB1 }\end{array}$ \\
\hline $\begin{array}{l}\text { 7. CITROBACTER } \\
\text { FREUNDIN }\end{array}$ & 5 & $\begin{array}{c}\text { PB2 } \mathrm{CO} 2 \text { MRO2 } \\
\text { IMP2 L1 CF2 CS2 } \\
\text { CZD1 PT1 AMC2 } \\
\text { TOB1 }\end{array}$ & $\begin{array}{c}\text { РВО СОO MRO3 IMP3 } \\
\text { CF3 CS3 CZD4 PT4 } \\
\text { AMC3 TOB4 }\end{array}$ \\
\hline \multicolumn{4}{|c|}{$\begin{array}{l}\text { PB - POLYMYXIN, CO - COLISTIN, MRO- MEROPENUM, IMP- IMPIPENUM, L- LEVOFLOXACIN, } \\
\text { OF- OFLOXACIN, CF- CEFIPIME, CS- CEFO+SULBCTM, CZD- CEFTAZIDIME, PT- PIPERA+TAZO, } \\
\text { AMC- AUGMENTIN, TOB- TOBRAMYCIN, LZ- LINEZOLID, VA- VANCOMYCIN, CD- CLINDAMYCIN, }\end{array}$} \\
\hline
\end{tabular}


Fig.1 Percentage of patients developing early onset and late onset VAP

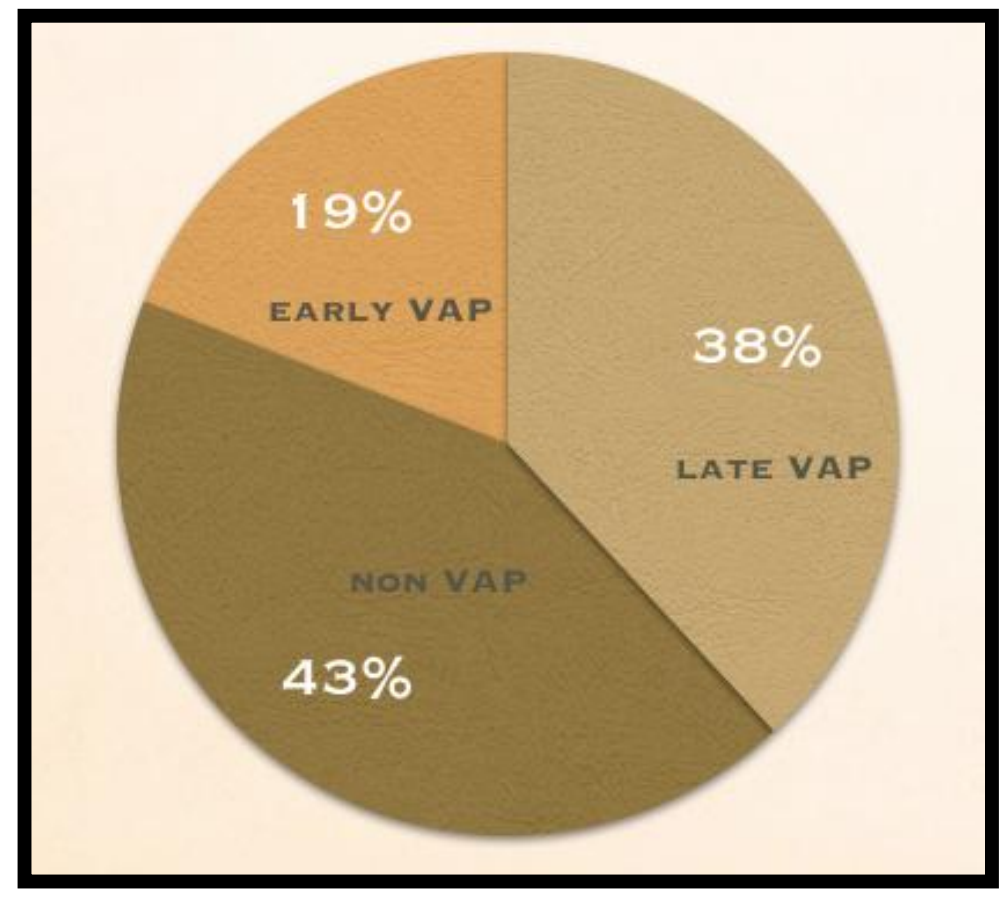

In 2016, Six et al., concluded that hyperaemia in ICU admitted patients was an independent risk factor for the development of VAP. Hyperoxemia at intensive care unit admission $(67 \%$ vs $53 \%, \mathrm{OR}=1.8,95 \%$ CI $(1.2,29)$, $p<0.05)$ and number of days spent with hyperoxemia were significantly more frequent in patients with VAP, compared with those with no VAP. ${ }^{12}$

In 2014, Ranjan et al., found that when considering the development of VAP in relation to the underlying condition, trauma was the most common, followed by COPD, respiratory failure and post operative illness. ${ }^{13}$

Prolonged administration of broad spectrum antibiotics was also seen as an underlying condition leading to VAP in ICU admitted patients of our study. Out of the 63 patients developing VAP, 14 patients had been taking antibiotics for the previous week prior to ICU admission. Furthermore, prolonged antibiotic administration to ICU patients for primary infection is thought to favour selection and subsequent colonization with resistant pathogens responsible for super infection. A sentinel study of VAP in a French ICU noted that prior antimicrobial therapy markedly increased the rate of VAP caused by $P$. aeruginosa and Acinetobacter spp. These two pathogens accounted for $65 \%$ of VAP cases among patients who have previously received antibiotics, compared with only $19 \%$ of VAP cases among antibiotic-naïve patients. ${ }^{14}$

In our study, antibiotic resistance to broad spectrum antibiotics like Beta-lactams, Carbapenems and aminoglycocides amongst gram negative bacteriae was encountered.

Out of the 21 isolates of A. baumanii, 11 isolates were found to be resistant to Carbapenems (Imipenem and Meropenem), 12 isolates were found to be resistant to Tobramycin, 11 isolates were found to be resistant to Piperacillin and Tazobactum. Out of the 18 isolates of $\mathrm{P}$. aeruginosa, 8 isolates were found to be resistant to Carbapenems (Imipenem and Meropenem), 9 isolates were 
found to be resistant to Tobramycin, 10 isolates were found to be resistant to Piperacillin and Tazobactum.

In 2018, Gupta et al., observed that among Acinetobacter spp. (32), a high level of resistance was seen to ciprofloxacin (81\%), amikacin (71.8\%), gentamicin $(70.7 \%)$, cefoperazone sulbactam $(59.3 \%)$, piperacillintazobactam (53.1\%), and imipenem (40.6\%), whereas less resistance was seen to cefotaxime (31.2\%) and cefepime (21.05\%). The resistance to meropenem was seen in $43.7 \%$ of the isolates. All the strains tested were sensitive to colistin and polymyxin B. Among Pseudomonas spp. (18), the isolates were mostly susceptible to colistin and polymyxin B (100\%), whereas a high level resistance was seen to antibiotics namely, cefoperazonesulbactam (88.8\%), gentamicin (88.8\%), ciprofloxacin (77.7\%), amikacin (72.2\%), piperacillin-tazobactam $\quad(55.5 \%), \quad$ and meropenem (50\%). Among Gram-positive cocci (5), three were E. faecalis, whereas two were MRSA and MSSA (Methicillin sensitive $S$. aureus), respectively. All were sensitive to vancomycin and linezolid. ${ }^{\mathbf{1 5}}$

In 2018, Patro et al., found that $28(60.87 \%)$ of the 46 bacterial isolates in VAP were MDR. AmpC $\beta$-lactamase was detected in 6 $(35.29 \%)$ and $6(26.08 \%)$ of nonfermenters and members of Enterobacteriaceae, respectively. Nearly $21.74 \% \quad(5 / 23)$ of Enterobacteriaceae were positive for ESBL. MBL were detected in both nonfermenters 3 (17.64\%) and Enterobacteriaceae 4 (17.39\%). About $75 \%$ (3/4) of MRSA and one methicillin-resistant CONS spp. were isolated from early-onset VAP. ${ }^{\mathbf{1 6}}$

In 2016, Mathai et al., observed that many of the isolated organisms in VAP patients exhibited resistance to the commonly used antibiotics and $26(27.3 \%)$ patients were found to be infected with multidrug-resistant (MDR) organisms. There were a high proportion of
Extended Spectrum $\beta$ Lactamases (ESBL) producing strains among Klebsiella species (13 isolates, $76.5 \%$ ) and E. coli (5 isolates, $55.55 \%)$ strains. While all strains of Acinetobacter were MDR organisms, 25 of these isolates $(43.1 \%)$ were resistant even to the carbapenem group of antibiotics. A significant number of Klebsiella (12 isolates, $70 \%$ ) and Pseudomonas (four isolates, 28.5\%) isolates also demonstrated resistance to carbapenems. ${ }^{17}$

The present study conclude that determination of the organism profile and their antibiotic sensitivity can go a long way in prescribing appropriate regimen which could be life saving. Another important aspect in VAP group of patients is that if the antibiotic therapy is delayed, there could be excessive mortality. Early report regarding antibiotic susceptibility patterns could be significant in deciding the antibiotic regimens. VAP is a serious problem in the ICU leading to longer hospital stay higher treatment costs and increased mortality and morbidity. Better knowledge of local patterns of pathogens causing VAP can help facilitate treatment choices. Local data collected the similar studies can assist in making informed treatment choices. To conclude, VAP due to a MDR Acinetobacter is one of the most dreadful complications that occur in the critical care setting. This poses serious problems in choosing the right antibiotic for the treatment of sick patients admitted into the ICU. Various strategies such as strict infection control measures, judicious prescribing of antibiotics, antibiotic resistance surveillance programs and antibiotic cycling are crucial to control infections due to these bacteria in patients admitted to ICU.

\section{Acknowledgement}

I would like to thank my guide Dr. Yogendra Kumar Tiwari for giving me an insight into this research article and helping me 
throughout in the journey of completion of this paper, my colleagues, technicians and other laboratory staff for helping me with the minutest detail while researching this article. I would also like to thank the Ethical Committee of my institution for giving me timely approval and permission to conduct the research.

\section{References}

Ventilator-associated pneumonia. Morehead RS, Pinto SJ Arch Intern Med. 2000 Jul 10; 160(13): 1926-36.

Clinical importance of delays in the initiation of appropriate antibiotic treatment for ventilator-associated pneumonia. Iregui M, Ward S, Sherman G, Fraser VJ, Kollef MHChest. 2002 Jul; 122(1): 262-8.

(Amartej S S, Baljit S B, Sharanjit S, Iqbal S, Vaneet M. Prospective Study of Ventilator Associated Pneumonia Incidence, Risk Factor, Outcome and its Prevention. J Anest and Inten Care Med. 2018; 5(4): 555666.

Ahmed Abdelrazik Othman, MohsenSalah Abdelazim, Ventilator-associated pneumonia in adult intensive care unit prevalence and complications. The Egyptian Journal of Critical Care Medicine, Volume 5, Issue 2, August 2017.

Patil HV, Patil VC. Incidence, bacteriology, and clinical outcome of ventilatorassociated pneumonia at tertiary care hospital. J Nat Sci Biol Med 2017; 8: 46-55.

Tracy Chin, Barry Kushner, Deonne DerschMills, and Danny J. Zuege, "Antibiotic Utilization Patterns in Patients with Ventilator-Associated Pneumonia: A Canadian Context," Canadian Journal of Infectious Diseases and Medical Microbiology, vol. 2016, Article ID 3702625, 10 pages, 2016.
Patil HV, Patil VC. Incidence, bacteriology, and clinical outcome of ventilatorassociated pneumonia at tertiary care hospital. J Nat Sci Biol Med 2017; 8: 46-55.

Mathai AS, Phillips A, Isaac R. Ventilatorassociated pneumonia: A persistent healthcare problem in Indian Intensive Care Units! Lung India 2016; 33: 5126.

Su Young Chi, Tae Ok Kim, Chan Woo Park, Jin Yeong Yu, Boram Lee, Ho Sung Lee, Yu Il Kim, Sung Chul Lim, Yong Soo Kwon Tuberc Respir Dis (Seoul) 2012 Jul; 73(1): 32-37.

Hina Gadani, Arun Vyas, Akhya Kumar Kar. A study of ventilator-associated pneumonia: Incidence, outcome, risk factors and measures to be taken for prevention. Indian J Anaesth. 2010 Nov-Dec; 54(6): 535-540.

Li Chang, Yun Dong, Ping Zhou. Investigation on Risk Factors of Ventilator-Associated Pneumonia in Acute Cerebral Hemorrhage Patients in Intensive Care Unit. Can Respir J. 2017; 2017: 7272080.

Sophie Six, Karim Jaffal, Geoffrey Ledoux, Emmanuelle Jaillette, Frédéric Wallet, Saad Nseir. Hyperoxemia as a risk factor for ventilator-associated pneumonia. Crit Care. 2016; 20: 195.

Neelima Ranjan, Uma Chaudhary, Dhruva Chaudhry, K. P. Ranjan. Ventilatorassociated pneumonia in a tertiary care intensive care unit: Analysis of incidence, risk factors and mortality. Indian J Crit Care Med. 2014 Apr; 18(4): 200-204.

Nosocomial pneumonia in patients receiving continuous mechanical ventilation. Prospective analysis of 52 episodes with use of a protected specimen brush and quantitative culture techniques. Fagon JY, Chastre J, Domart Y, Trouillet JL, Pierre J, Darne C, Gibert 
C Am Rev Respir Dis. 1989 Apr; Patro S, Sarangi G, Das P, Mahapatra A, 139(4): 877-84.

Gupta V, Singla N, Gombar S, Palta S, Chander J. Prevalence of multidrugResistant Pathogens and Their Antibiotic Susceptibility Pattern from Late-Onset Ventilator-Associated Pneumonia Patients from a TertiaryCare Hospital in North India. J Assoc Chest Physicians 2018; 6: 4-11. Mohapatra D, Paty BP, Chayani N. Bacteriological profile of ventilatorassociated pneumonia in a tertiary care hospital. Indian $\mathbf{J}$ Pathol Microbiol 2018; 61: 375-9.

Mathai AS, Phillips A, Isaac R. Ventilatorassociated pneumonia: A persistent healthcare problem in Indian Intensive Care Units! Lung India 2016; 33: 5126.

\section{How to cite this article:}

Yogendra Kumar Tiwari and Adhunika Singh. 2019. Prevalence and Antibiotic Susceptibility Pattern of Pathogens Causing Ventilator-Associated Pneumonia in Patients attending a Tertiary Care Hospital in South-Eastern Rajasthan. Int.J.Curr.Microbiol.App.Sci. 8(11): 2602-2610. doi: https://doi.org/10.20546/ijcmas.2019.811.301 